\title{
Introduction to the Second Section of the Special Issue: Invited Papers from the 2015 APAHC Conference
}

\author{
Laura A. Shaffer ${ }^{1}$ - Amit A. Shahane ${ }^{2}$
}

Published online: 17 February 2016

(c) Springer Science+Business Media New York 2016

This issue of the Journal of Clinical Psychology in Medical Settings includes a continuation of the special issue of Invited Papers based on presentations at the 2015 conference of the Association of Psychologists in Academic Health Centers (APAHC). The first installment of this special issue was published in December 2015. APAHC is an organization devoted to representing the interests and providing professional support and networking for psychologists working in Academic Health Centers (AHCs). Our biennial conference highlights the multiple aspects of our work in AHCs including clinical service, teaching, and research, as well as matters concerning the business of practice and professional identity for psychologists in these settings. The 2015 conference was held in Atlanta, Georgia in February with the theme, "Academic Health Centers in the Era of Interprofessionalism: Multifaceted Contributions of Psychology." A complete overview of the conference is available in the introduction to the December special issue of JCPMS (Shaffer \& Shahane, 2015). Because the APAHC conference tends to be fairly small relative to the estimated nearly 5000 psychologists practicing in academic health centers across the United States (Robiner, Dixon, Miner, \& Hong, 2014), we followed the conference with these special issues of JCPMS to disseminate this highly pertinent information more broadly.

Laura A. Shaffer

laura.shaffer@virginia.edu

1 Department of Pediatrics, University of Virginia School of Medicine, P.O. Box 800828, Charlottesville, VA 22908, USA

2 Department of Psychiatry and Neurobehavioral Sciences, University of Virginia School of Medicine, Charlottesville, VA, USA
Manuscripts published in the two sections of the special issue reflect themes related to expanding psychologists' work through telehealth; capturing the value of psychologists' clinical, administrative, and educational work; patient centered medical homes and integrated care; and professional development. The December 2015 section of the special issue included five manuscripts addressing psychologists' roles in patient centered medical homes, measuring clinical and administrative outcomes, transformational leadership, and psychology licensure implications of telehealth. The current section has three manuscripts, one of which gives a broad overview of professional development issues and the other two of which address more specific administrative issues. In their article titled "Psychologists in Academic Health Centers: Being, Visible, Relevant, and Integral," Barry Hong and William Robiner discuss how early and mid-career psychologist can thrive in AHCs. Eugene D'Angelo and Katie Gallagher's article, "Capturing Psychologists' Work in Academic Health Settings: The Role of the Educational Value Unit (EVU)," reviews how psychologists have been historically compensated, as well as alternative models that incorporate the many facets of psychologists' work pertaining to education in AHCs. Last, Samuel Hubley and Benjamin Miller discuss the "Implications of Healthcare Payment Reform for Clinical Psychologists in Medical Settings" and give an overview of promising alternative payment models in integrated care.

As the 2015 conference co-chairs and guest editors of the corresponding special issue of JCPMS, we are keenly aware of the power of the APAHC community and grateful to our many colleagues who had hands in the success of these ventures. First, we would like to thank our esteemed colleagues who contributed doubly by presenting in Atlanta and writing manuscripts for the special issue. 
Second, thank you to the APAHC Board and the 2015 conference sponsors: the National Register, the American Board of Professional Psychology, Health Psychology (Division 38), the Society for Clinical Neuropsychology (Division 40), and Taylor Study Method. Third, we are grateful for the mentoring we received from the Editor in Chief of JCPMS, Gerald Leventhal, and from so many others in APAHC over these last 5 years of conference planning and journal editing. Last-we cannot mention them enough!- - kudos and extraordinary thanks to our 2015 conference committee: Liz Cash, Kristine Diaz, Teresa Fecteau, Lauren Penwell-Waines, Stephanie Power, and our student volunteer Neha Khorana. We look forward to future endeavors and encourage readers new to APAHC to become involved in this distinguished organization.

\section{Compliance with Ethical Standards}

Conflict of Interest Laura A. Shaffer and Amit A. Shahane declare that they have no conflict of interest.
Human and Animal Rights and Informed Consent This manuscript does not report research involving human or animal participants. Informed consent was not required.

\section{References}

Robiner, W. N., Dixon, K. E., Miner, J. L., \& Hong, B. A. (2014). Psychologists in medical schools and academic medical centers: Over 100 years of growth, influence, and partnership. American Psychologist, . doi:10.1037/a0035472.

Shaffer, L. A., \& Shahane, A. A. (2015). Introduction to the special issue: Invited papers from the 2015 APAHC conference. Journal of Clinical Psychology in Medical Settings, 22(4), 195-198. doi:10.1007/s10880-015-9446-3. 